(i.e. knowing which healthcare professionals they need), dealing with information (i.e. knowing how to identify relevant sources). Patients do lots of experiments (changing their DMARD dosage on their own initiative, trying alternative medicine or food exclusions...) and ritualizing their DMARDs administration. Such rituals represent a reflexive moment for the patients dedicated to themselves and their disease.

During the stage of stabilized disease and treatment, rituals tend to improve observance but also increase safety problems because of habits, over-confidence, and forgetting of risky situations. Patients renew interest about safety concerns in case of an unexpected complication.

Conclusions: Starting from the patients' point of view, this ethnographic study emphasizes a tension between observance and safety. Practices by which patients appropriate their treatment create habits that improve observance but also increase safety problems. It seems necessary to support the patients in updating their safety skills. A SP App could contribute to this goal only if its use finds its place in the patients' ritual.

Acknowledgements: Grant: French Society of Rheumatology with institutional funding by Biogen, Nordic Pharma, Roche

Disclosure of Interest: None declared

DOI: 10.1136/annrheumdis-2017-eular.5368

\section{THU0587 PUBLIC AWARENESS OF RHEUMATIC DISEASES IN CYPRUS - NEED FOR IMPROVEMENT}

J. Joseph ${ }^{1,2}$, I. Armata ${ }^{1}$, A. Antoniadou ${ }^{1}$, P. Maini ${ }^{1} .{ }^{1}$ St. George's University of London Programme, University of Nicosia Medical School; ${ }^{2}$ Rheumatology, Aretaeion Hospital, Nicosia, Cyprus

Background: Public awareness regarding rheumatic diseases is a constant aim of patient societies and health care professionals in rheumatology. A high level of awareness will help identification and early treatment, it would avoid unnecessary investigations and costs and more importantly, it would assist functioning of patients with such conditions in society, with the understanding and support they deserve.

Objectives: The aim was to study public awareness regarding rheumatic conditions. Specifically, what constitutes a rheumatic condition, which doctor deals with these, what is their frequency and what age groups are affected. Methods: During the rheumatic diseases awareness week in May 2016, doctors, medical students and members of the Cyprus League against Rheumatism, walked the streets of major cities and invited passers-by to answer a few simple questions. This was optional and at the end of the questions, information was provided, based on the answers and on any additional queries raised by people. Results: 400 people provided answers. There were slightly more women than men and ages ranged from 13 to 86 years. Almost $50 \%$ did not know what a rheumatologist does. Only $11 \%$ could name 3 rheumatic conditions. Although the majority stated that rheumatic diseases occur in the elderly, 2/3 were unaware that they can affect children. Most people correctly identified which specialists should deal with asthma or eczema, but a huge majority did not know who should be consulted for back pain, tendon problems or osteoporosis. Although $75 \%$ had heard of rheumatoid and osteoarthritis, $75 \%$ of people had never heard of ankylosing spondylitis or fibromyalgia and only about half had heard of psoriatic arthritis or lupus. Most people stated that rheumatic conditions in general, affect $10-20 \%$ of people.

Conclusions: There was significant lack of awareness as to what rheumatologists do, what constitutes a rheumatic disease, the fact that it affects young people and the link between rheumatology and back pain, tendon problems and osteoporosis. All these points need to be included in public education. Of the major rheumatic diseases, the next awareness campaign needs to include ankylosing spondylitis, fibromyalgia, psoriatic arthritis and lupus.

Disclosure of Interest: None declared

DOI: 10.1136/annrheumdis-2017-eular.2172

\section{THU0588 ARE RHEUMATOID ARTHRITIS PATIENTS WILLING TO USE AN E-HEALTH INTERACTIVE SELF-ASSESSMENT WEBSITE? ANALYSES OF 159 PATIENTS FROM A RANDOMISED CONTROLLED TRIAL OVER 12 MONTHS}

L. Gossec ${ }^{1}$, A. Cantagrel ${ }^{1}$, M. Soubrier ${ }^{1}$, J.M. Joubert ${ }^{2}$, W. Czarlewski ${ }^{2}$, B. Combe $^{1}$, J.M. Berthelot ${ }^{1}$, D. Wendling ${ }^{1}$, E. Dernis ${ }^{1}$, L. Grange ${ }^{1}$, C. Beauvais ${ }^{1}$, A. Perdriger ${ }^{1}$, H. Nataf ${ }^{1}$, M. Dougados ${ }^{1}$, H. Servy ${ }^{1}$. ' ${ }^{1}$ CarNET Study Group, Paris; ${ }^{2}$ UCB Pharma, Colombes, France

Background: Interactive, online electronic (e)-health services with patientreported outcome measure (PROM)-based instruments may be helpful for patients (pts). Sanoïa is a secure, independent e- and mobile (m)-health platform developed to allow pt self-assessment, storage of questions to ask physicians, and self-monitoring of disease status. The platform offers a dedicated set of scores, PROMs and information about different diseases, including rheumatoid arthritis (RA)

Objectives: To characterise pts with RA who chose to access e-health services regularly over a 12-month (mo) period.

Methods: Post-hoc analysis of CarNET (NCT02200068): a French, multicentre, 12-mo randomised controlled trial. Pts with RA were randomised to: access to
Sanoïa (30-min training via the telephone with no further incentive to access the platform) or usual care (normal internet use without access to Sanoïa). The Sanoïa group pts used a home-based e-Case Report Form to record frequency of Sanoïa access, satisfaction with the platform ( $0-10$ scale; $0=$ completely satisfied, $10=$ not satisfied), and barriers to use (from a pre-specified list). Baseline pt characteristics associated with more frequent use (above the median) were analysed by univariate and multivariate logistic regression.

Results: 159 RA pts were randomised to the Sanoïa arm: mean $\pm S D$ age was $56.1 \pm 13.1$ years, disease duration was $15.0 \pm 11.5$ years and $132(83.0 \%)$ of pts were female. Mean DAS28 was $2.7 \pm 1.2$ with $57.2 \%$ of pts in remission; $115(72.3 \%)$ were taking a biologic; $23.3 \%$ had attended therapeutic education sessions; $15.7 \%$ were members of pt associations; and $53.5 \%$ had participated in university-level studies. Overall, 41 pts (25.7\%) never accessed Sanoïa and $81(50.9 \%)$ accessed the platform at least twice; median $=2$, mean $\pm S D=4.4 \pm 11.3$ connections/pt over the 12 mos. 54 pts $(34.0 \%)$ used Sanoïa for $\geq 2$ mos with a noticeable investigator effect $(0.3 \pm 0.2,0-1$ scale). Mean satisfaction with the platform was very high $(1.5 \pm 1.5)$, with $90 \%$ scoring satisfaction $\leq 3$. One barrier was expressed in $11.8 \%$ of cases: "the platform is not useful for me since I am in remission". In multivariate analysis, the only variable associated with greater usage of Sanoïa was being a member of a pt association: odds ratio [95\% $\mathrm{Cl}]=1.44[1.17-1.77]$

Conclusions: A quarter of pts who participated in this trial to assess e-health did not access the platform whereas half accessed the platform at least twice. Pts expressed high satisfaction and the only barrier was lower usefulness when in remission. e-Health is a promising tool for self-management in RA. The impact of offering additional services should also be explored in a further study.

Acknowledgements: This study was funded by UCB Pharma. We thank the patients and their caregivers in addition to the investigators and their teams who contributed to this study. Editorial services were provided by Costello Medical Consulting.

Disclosure of Interest: L. Gossec Grant/research support from: UCB Pharma Lilly, Consultant for: AbbVie, BMS, Celgene, Janssen, Novartis, MSD, UCB A. Cantagrel: None declared, M. Soubrier: None declared, J. M. Joubert Employee of: UCB Pharma, W. Czarlewski Employee of: UCB Pharma, B. Combe Grant/research support from: Merck Pfizer Inc, Roche-Chugai, Consultant for: Merck, Pfizer, Roche-Chugai, UCB Pharma, Bristol-Myers Squibb, Celgene, Eli Lilly, Speakers bureau: Merck, Pfizer, Roche-Chugai, UCB Pharma, Bristol-Myers Squibb, Celgene, Eli Lilly, Novartis, J. M. Berthelot: None declared, D. Wendling: None declared, E. Dernis: None declared, L. Grange: None declared, C. Beauvais Speakers bureau: UCB Pharma, A. Perdriger: None declared, H. Nataf: None declared, M. Dougados Grant/research support from: UCB Pharma, AbbVie, Pfizer, Lilly, Merck, Novartis, H. Servy Shareholder of: Sanoïa platform operating company: e-health services, Employee of: Sanoïa

DOI: 10.1136/annrheumdis-2017-eular.1972

\section{THU0589 PATIENT-PERCEIVED COPING WAS ASSOCIATED WITH PATIENT-PERCEIVED QUALITY OF PATIENT-PHYSICIAN INTERACTIONS IN 320 PATIENTS WITH RHEUMATOID ARTHRITIS}

L. Gossec ${ }^{1}$, C. Desthieux ${ }^{1}$, A. Cantagrel ${ }^{1}$, M. Soubrier ${ }^{1}$, J.M. Berthelot ${ }^{1}$, J.M. Joubert ${ }^{2}$, B. Combe ${ }^{1}$, W. Czarlewski ${ }^{2}$, D. Wendling ${ }^{1}$, E. Dernis ${ }^{1}$, L. Grange ${ }^{1}$, C. Beauvais ${ }^{1}$, A. Perdriger ${ }^{1}, \mathrm{H}$. Nataf $^{1}$, M. Dougados ${ }^{1}, \mathrm{H}$. Servy ${ }^{1}$ ${ }^{1}$ CarNET Study Group, Paris; ${ }^{2}$ UCB Pharma, Colombes, France

Background: There has been growing emphasis on the importance of shared decision-making in rheumatoid arthritis (RA). ${ }^{1,2}$ Patient-physician (pt-phy) shared decision-making necessitates open and thorough discussions and good interactions.

Objectives: This analysis explored pt-perceived quality levels of pt-phy interactions and characteristics of pts when these interactions are described as very good by pts.

Methods: CarNET (NCT02200068) was a French, 12-month, multicentre randomised controlled trial to assess access to an e-health platform (Sanoïa) allowing self-assessment of disease. ${ }^{1,2}$ This was a post-hoc analysis, using baseline data only. Pts had confirmed RA and were enrolled by their treating rheumatologist. Pt-perceived pt-phy interactions were assessed through the pt-reported questionnaire Perceived Efficacy in Patient-Physician Interactions (PEPPI-5) ${ }^{3}$ which consists of 5 items, each starting with "How confident are you in your ability to ..." (eg. "... know what questions to ask a doctor?"). Pts rated each item on an 11-point scale; $0=$ not at all confident, $10=$ very confident. Total PEPPI-5 scores range from 0-50; higher scores represent higher perceived self-efficacy in pt-phy interactions. Factors associated with a higher PEPPI-5 (ie. > median) were analysed by univariate and multivariate logistic regression (factors included pt demographics, phy demographics, disease characteristics and activity including pt-perceived coping [scored 0-10 in the Rheumatoid Arthritis Impact of Disease (RAID) questionnaire; lower scores indicate better coping]).

Results: Of 320 RA pts (159 vs 161; Sanoïa vs usual care), mean \pm SD age was $57.0 \pm 12.7$ years, disease duration was $14.6 \pm 11.1$ years and $253(79.1 \%)$ were female. Mean DAS28 was $2.7 \pm 1.2,54.1 \%$ were in DAS28 remission $(<2.6)$; $216(67.5 \%)$ were taking a biologic; $21.9 \%$ had previous therapeutic education sessions; $15.3 \%$ were members of pt associations; and $51.9 \%$ had followed university-level studies. The mean \pm SD PEPPI-5 score was $39.2 \pm 7.8$ and the 
median was 40 . In univariate analyses, associations with $p<0.05$ were observed between pt-perceived coping $(p=0.0008)$, erosive disease $(p=0.03)$ and DAS28 remission $(p=0.05)$ and a high PEPPI-5; associations with $p<0.2$ were observed for older age $(\mathrm{p}=0.07)$ and $\mathrm{HAQ}-\mathrm{DI} \leq 0.5(\mathrm{p}=0.12)$. In multivariate analyses, the only factor associated with high PEPPI-5 was pt-perceived coping (odds ratio $[95 \% \mathrm{Cl}]=0.85[0.76-0.96] ; \mathrm{p}=0.007$ )

Conclusions: Among RA pts whose disease was well controlled, pt-perceived pt-phy interactions were good. Pt-perceived coping was associated with better pt-perceived pt-phy interactions, indicating that perhaps pts who felt in control were more at ease with their phy, or vice-versa. The data did not allow us to attribute causality. These elements are important in the shared decision-making process.

References:

[1] www.sanoia.com

[2] Gossec L. Arthritis Rheum 2016;68:S10.

[3] ten Klooster P. Patient Educ Couns 2012;87(1):125-30.

Acknowledgements: This study was funded by UCB Pharma. We thank the patients and their caregivers in addition to the investigators and their teams who contributed to this study. Editorial services were provided by Costello Medical Consulting.

Disclosure of Interest: L. Gossec Grant/research support from: UCB Pharma, Lilly, Consultant for: AbbVie, BMS, Celgene, Janssen, Novartis, MSD, UCB, C. Desthieux: None declared, A. Cantagrel: None declared, M. Soubrier: None declared, J. M. Berthelot: None declared, J. M. Joubert Employee of: UCB Pharma, B. Combe Grant/research support from: Merck Pfizer Inc, Roche-Chugai, Consultant for: Merck, Pfizer, Roche-Chugai, UCB Pharma, Bristol-Myers Squibb, Celgene, Eli Lilly, Speakers bureau: Merck, Pfizer, Roche-Chugai, UCB Pharma, Bristol-Myers Squibb, Celgene, Eli Lilly, Novartis, W. Czarlewski Employee of: UCB Pharma, D. Wendling: None declared, E. Dernis: None declared, L. Grange: None declared, C. Beauvais Speakers bureau: UCB Pharma, A. Perdriger: None declared, H. Nataf: None declared, M. Dougados Grant/research support from: UCB Pharma, AbbVie, Pfizer, Lilly, Merck, Novartis, H. Servy Shareholder of: Sanoïa platform operating company: e-health services, Employee of: Sanoia DOI: 10.1136/annrheumdis-2017-eular.1973

\section{THU0590 THE USE OF A PORTFOLIO AMONG YOUNG RHEUMATOLOGISTS: RESULTS OF AN EMEUNET SURVEY}

M. Van Onna ${ }^{1}$, F. Sivera ${ }^{2}$, V. Navarro-Compán ${ }^{3}$, E. Nikiphorou ${ }^{4}$, A. Moltó ${ }^{5}$ S. Ramiro ${ }^{6}$ on behalf of the EMEUNET Working Group. ${ }^{1}$ Department of Internal Medicine, division of Rheumatology, Maastricht University Medical Center +, Maastricht, Netherlands; ${ }^{2}$ Rheumatology, Hospital General Universitario de Elda, Alicante; ${ }^{3}$ Rheumatology, la Paz University Hospital, Madrid, Spain;

${ }^{4}$ Rheumatology, Whittington Hospital, London, United Kingdom; ${ }^{5}$ Rheumatology, Cochin Hospital, René Descartes University, Paris, France; ${ }^{6}$ Rheumatology, Leiden University Medical Center, Leiden, Netherlands

Background: Portfolios are increasingly used in medical education. A portfolio may stimulate deep learning, deliver summative assessment and encourage reflection on clinical practice. A portfolio is seen as the key connection between learning at the organizational and the individual level.

Objectives: To (1) explore the perceptions of young rheumatologists about the use of a portfolio and to (2) study the barriers and facilitators when implementing a portfolio at a national and international level.

Methods: A survey was sent by email to all EMEUNET (Emerging EULAR Network) members. EMEUNET is a group of young rheumatologists and researchers within EULAR-member countries. Descriptive statistics were used to analyse initial data collected (Nov-Dec 2016). Weighted averages were calculated (i.e. mean in which each item being averaged is multiplied by a number (weight) based on the item's relative importance).

Results: 132 participants responded $(64 \%$ female; mean age 33.5 years (SD 4.3 years); 34 countries). In total, $56.3 \%$ of participants were working as rheumatologists; $32.8 \%$ were rheumatologists in training. $49.6 \%$ of the participants indicated that a portfolio was already used by rheumatology fellows working at their institution; in $71.9 \%$ of these cases, this portfolio was also used at a national level. $50.4 \%$ of participants did not use a portfolio during their training; of these, $86.7 \%$ (strongly) agreed that a portfolio might be a useful tool.

Several barriers for successful implementation of a portfolio were identified by the participants. The main barrier was that a portfolio was not developed at a national level, and if developed at a national level, there were often no incentives to use it (Table 1). According to participants, the top 3 competencies that should be collected and reflected upon in the portfolio were (weighted average; importance 0 (not important) - 10 (extremely important)): practical skills (e.g. ultrasound) (8.2); correct use of diagnostics and therapeutic armamentarium (7.9); clinical skills (e.g. history taking) (7.8). The skills chosen as the least important to be included in a portfolio were: information on management tasks (6.5); promoting hospital-based care (e.g. writing a protocol) (6.6); theoretical and clinical knowledge (6.7).

Conclusions: A portfolio is generally considered a valuable tool and half of the participants already work with it. However, several barriers may prevent optimal implementation. Developing a core set of rheumatology-oriented competencies and a template for a portfolio to be used across institutions and eventually countries could promote implementation and harmonize training.

Disclosure of Interest: None declared
Table 1. Perceived barriers with regard to the implementation of a portfolio.

\begin{tabular}{|l|l|}
\hline Barrier & $\begin{array}{l}\text { Response* } \\
\text { (n=122) }\end{array}$ \\
\hline Participants who work/ed with a portfolio (n= 58) & $50.0 \%$ \\
\hline No incentives to use it & $46.6 \%$ \\
\hline Limited time & $31.0 \%$ \\
\hline Lack of clarity about how and when to use it & $29.3 \%$ \\
\hline Lack of interest by stake holders & $12.1 \%$ \\
\hline Difficult to access the required forms & \multicolumn{2}{|l}{} \\
\hline Participants who did not work/ed with a portfolio (n=64) & $51.6 \%$ \\
\hline Portfolio not developed on national level & $21.9 \%$ \\
\hline No added value recognized to it & $12.5 \%$ \\
\hline Initiatives, but lack of clarity about how and when to use it & $9.4 \%$ \\
\hline Initiatives, but no incentives to use it & \\
\hline *More than one answer allowed. 10 (7.6\%) participants did not answer the question.
\end{tabular}

DOI: 10.1136/annrheumdis-2017-eular.2280

\section{THU0591 ASSESSING THE READABILITY AND PATIENT COMPREHENSION OF MEDICINE INFORMATION SHEETS PROVIDED TO PATIENTS BY AUSTRALIAN RHEUMATOLOGISTS}

M. Oliffe $^{1}$, J. Johnston ${ }^{2}$, D. Freeman ${ }^{1}$, H. Bagga ${ }^{1}$, P.K. Wong ${ }^{3} .{ }^{1}$ Mid-North Coast Arthritis Clinic, MNCAC; ${ }^{2}$ Faculty of Education, Southern Cross University; ${ }^{3}$ Mid-North Coast Arthritis Clinic, UNSW Rural Clinical School, Coffs Harbour, Australia

Background: Literacy is "the ability to read and use written information and to write appropriately in a range of contexts". ${ }^{1}$ Low literacy is associated with poorer health outcomes, including increased mortality. ${ }^{2}$ Those accessing the healthcare system require adequate literacy to understand written instructions regarding medication, appointments and medication doses. We have previously shown in $>200$ rural and urban Rheumatology patients that $<15 \%$ of patients had low health literacy and $<1 / 3$ of patients incorrectly followed dosing instructions for common Rheumatology drugs. ${ }^{3}$ Up to $24 \%$ of US Rheumatology patients had a reading level of $\leq 8$ th grade. ${ }^{4}$ These findings are concerning, as Rheumatologists often use medications such as MTX or bDMARDS with severe side effects. Rheumatologists often provide written information regarding these medications to patients.

Objectives: To assess i) the readability of Patient Medicine Information Sheets (PMIS) regarding medications provided to patients by Australian Rheumatologists, and ii) patient comprehension of these documents.

Methods: Thirty-one English-language PMIS from the Australian Rheumatology Association (ARA) website were assessed for readability using Readability Studio ${ }^{T M}$ (Oleander Software). This software uses the number of sentences, words, syllables and characters in a sample of writing to estimate the required grade level and reading age of the target population using several readability scales (eg Flesch scale, Gunning Fog and Simple Measure of Gobbledygook, or SMOG).

To assess comprehension, a random sample of 100 patients from MNCAC was asked to read an ARA PMIS about one of the following medications: MTX, NSAIDS, Adalimumab, Abatacept or prednisone. He/she then answered five multiple choice questions about the content. A time limit of 15 minutes for reading the PMIS and answering the questions was allowed.Approval was obtained from the local HREC as a low/negligible risk project. Results are expressed as mean \pm sem.

Results: The mean Flesch scale value (range $0-100,0=$ very confusing; $100=$ very easy) of the 31 PMIS assessed was $51.1 \pm 0.6$ (fairly difficult). The mean FORCAST grade level and reader age was $11 \pm 0$ and $16-17$ years, respectively. The mean Gunning Fog grade level was $11.4 \pm 0.1$ with a reader age of $16-17$ years. The mean SMOG grade level was $11.8 \pm 0.1$ with a mean reader age of $16-17$ years. At time of writing, comprehension was assessed in 7 of the planned 100 patients. So far, the mean number of correct answers was $3.2 \pm 0.5$ (max. score of 5).

Conclusions: The ARA PMIS are suitable for readers who have completed a grade level $\geq 11$ with a reading age $\geq 16$ years. A low literacy population $(<$ grade 8) will probably struggle to understand the content. These findings need to be extended to the PMIS used in other countries and has implications for the design of better patient information material.

References:

[1] Australian Government, Department of Education Employment and Training. The Australian Language and Literacy Policy. Canberra 1991.

[2] Baker DW et al. Arch Intern Med 2007:167:1503-1509.

[3] Wong PK et al. Medicine (Baltimore) 2014 Nov;93(25):e129.

[4] Swearingen CJ et al. J Clin Rheumatol 2010;16:359-364.

Disclosure of Interest: None declared

DOI: 10.1136/annrheumdis-2017-eular.4811 